\title{
Harşit Vadisi'nin Hermannia Nicolet, 1855 ve Hermanniella Berlese, 1908 (Acari, Oribatida) türleri üzerine taksonomik araştırmalar
}

\section{Taxonomic investigations on Hermannia Nicolet, 1855 and Hermanniella Berlese, 1908 (Acari, Oribatida) species of the Harşit Valley}

\author{
Zehra KARABÖRKLÜ 1 Nusret AYYILDIZ² \\ Abstract
}

Oribatid mites are organisms that live in a wide variety of habitats, constitute the largest part of the small arthropods in these habitats and play an important role in the decomposition process. From them, taxa belonging to the genera Hermannia Nicolet, 1855 and Hermanniella Berlese, 1908, were evaluated in taxonomical point, by extracted from the samples collected from the Harşit Valley in 2013 and 2014. As a result of the assessment, totally three species were determined. Of these, Hermanniella picea (Koch, 1839) is a new record for the Turkish fauna; Hermannia (Hermannia) gibba Koch, 1839 and Hermanniella dolosa Grandjean, 1931 were found out previously known taxa from Turkey. Extraction of oribatid mites from materials such as collected soil, foliage, undergrowth, lichen, algae, tree bark were made using the Berlese-Tullgren funnel system. Selected mites were fixed and stored in $80 \%$ ethyl alcohol. Light and scanning electron microscopes were used in the diagnosis and examination of mite samples. As a result, scanning electron microscope photos of all determined taxa were taken. Their morphological features were reviewed on the basis of our samples. Furthermore, the identification keys to the genera and species were arranged.

Keywords: Oribatid mites, taxonomy, new record, Harşit Valley, Turkey

\section{Öz}

Oribatid akarlar; çok çeşitli habitatlarda yaşayan, bu habitatlarda küçük eklembacaklıların en büyük kısmını oluşturan ve ayrışma işleminde önemli rol oynayan organizmalardır. Onlardan Hermannia Nicolet, 1855 ve Hermanniella Berlese, 1908 cinslerine ait taksonlar, 2013 ve 2014 yıllarında Harşit Vadisi'nden toplanan örnekler içerisinden seçilerek taksonomik bakımdan değerlendirildi. Yapılan değerlendirme sonucunda toplam üç tür tespit edildi. Bunlardan Hermanniella picea (Koch, 1839) Türkiye faunası için yeni kayıt olarak, Hermannia (Hermannia) gibba Koch, 1839 ve Hermanniella dolosa Grandjean, 1931 ise daha önce Türkiye'den bilinen taksonlar olarak tespit edildi. Toplanan toprak, yaprak döküntüsü, orman altı bitkileri, liken, yosun, ağaç kabuğu gibi materyalden oribatid akarların seçilmesi Berlese-Tullgren huni düzeneği kullanılarak yapıldı. Seçilen akarlar \%80'lik etil alkolde tespit edildi ve depolandı. Akar örneklerinin teşhisi ve incelenmesinde ışık ve tarama elektron mikroskopları kullanıldı. Sonuç olarak; belirlenen taksonların tarama elektron mikroskobunda fotoğrafları çekildi, örneklerimiz üzerinden tanımları gözden geçirildi. Ayrıca Türkiye'den bilinen cins ve türler için teşhis anahtarları düzenlendi.

Anahtar sözcükler: Oribatid akarlar, taksonomi, yeni kayıt, Harşit Vadisi, Türkiye

1 Erciyes Üniversitesi, Fen Bilimleri Enstitüsü, Biyoloji Anabilim Dalı, 38030, Kayseri

2 Erciyes Üniversitesi, Fen Fakültesi, Biyoloji Bölümü, 38030, Kayseri

* Sorumlu yazar (Corresponding author) e-mail: nayildiz@erciyes.edu.tr

Alınış (Received): 16.04.2019 Kabul ediliş (Accepted): 08.08.2019 


\section{Giriş}

Toprak faunasının önemli canlı gruplarından birini oluşturan akarların, hem Parasitiformes hem de Acariformes üst takımına ait bazı bireyleri toprak-döküntü sisteminde serbest olarak yaşamlarını sürdürürler. Bunlar arasında Acariformes üst takımında yer alan oribatid akarlar çeşitlilik bakımından en zengin grubu oluşturmaktadır (Norton \& Behan-Pelletier, 2009). Vücut uzunlukları genellikle $300-700$ $\mu \mathrm{m}$ arasında olup renksiz veya sarıdan kırmızımtırak renge kadar değişebilen renktedir. Çoğunlukla çürükçül veya mantarlarla beslenen organizmalar olmaları nedeniyle organik maddenin ayrışmasını düzenleyerek ve toprak içindeki mikroorganizmaları yayarak topraktaki besin döngüsünde ve toprak oluşumunda önemli rol oynarlar (Marshall et al., 1987; Norton, 1990; Evans, 1992; Wissuwa et al., 2013 Dhooria, 2016). Bu bakımdan, sağıklı toprakların iyi bir belirteci olarak hizmet ederler. Oribatid akarlar; yoğun olarak organik maddenin bol olduğu orman toprakları ve döküntüde bulunmalarının yanı sıra tuzlu ve tatı sularda, mağaralarda, kemirgen yuvalarında, kuş yuvalarında, ağaçlarda ve hatta insanların yaşadığı yerlerde de bulunurlar (Norton \& Behan-Pelletier, 2009; Dhooria, 2016). Oribatid akarlar genellikle sert ve kuvvetli bir dış iskelete sahip olmaları nedeniyle avcılığa nispeten az maruz kalırlar. Fakat belirli karınca türleri, kınkanatılır ve küçük semenderlerin özel olarak bu akarlar ile beslendikleri rapor edilmiştir (Masuko, 1994; Dhooria, 2016).

Oribatid akarlar; toprak akarları içerisinde tür çeşitliliği bakımından en zengin gruplardan birini oluşturmakta olup tüm zoocoğrafik bölgelerde yayılış göstermektedir. Şimdiye kadar tanımlanmış 10.923 tür ve alttürü bilinmektedir (Subias, 2004, updated 2018). Hermanniidae Sellnick, 1928 dünyada 3 cins, 2 altcins ve 113 tür ile temsil edilmekte olup Antarktika hariç kozmopolit dağılışa sahiptir. Bu familyaya ait olup burada incelenen Hermannia Nicolet, 1855 kozmopolit dağılışa sahiptir ve 111 tür ile familyanın en zengin grubunu temsil etmektedir (Subias, 2004, updated 2018). Ülkemizde şimdiye kadar sadece Hermannia (s. str.)'ya ait Hermannia ( H.) gibba (Koch, 1839), Erzurum ili Uzunoluk ormanında yaşayan bazı oribatid akarlar ve bunlardan izole edilen funguslar üzerine yapılan bir çalışmada tespit edilmiştir (Yalçın et al., 2013). Hermanniellidae Grandjean, 1934 dünyada 9 cins, 63 tür ve 2 alttür ile temsil edilmekte olup Antarktika hariç kozmopolit dağılışa sahiptir. Familyanın bu çalışmada incelenen cinsi Hermanniella Berlese, 1908 dünyada 40 tür ve bir alttür ile temsil edilmekte olup Neotropikal ve Antarktika hariç kozmopolit dağılışa sahiptir (Subias, 2004, updated 2018). Ülkemizde bu cinse ait $H$. multipora Sitnikova, 1973 Artvin ilinden ve $H$. dolosa Grandjean, 1931 (Daha önce Türkiye'den $H$. punctulata Berlese, 1908 olarak verilmiş.) Yozgat Çamlığı Milli Parkı'ndan kaydedilmiştir (Toluk et al., 2006; Ayyıldız \& Toluk, 2016).

Araştırma alanı olarak seçilen Harşit Vadisi; yeryüzü şekilleri ve iklim özellikleri bakımından üçe ayrıır: 1) Karasal iklime sahip Yukarı Harşit Vadisi, 2) Nemli-ılıman iklime sahip Aşağı Harşit Vadisi ve 3) İkisi arasında geçit teşkil eden Orta Harşit Vadisi (Pekin, 2013). İklim ve yeryüzü şekillerindeki bu farklılıklar ortam heterojenitesini olumlu yönde etkilemektedir. Dolayısıyla araştırma alanının biyolojik çeşitlilik bakımından zengin olması da kaçınılmazdır. Buna karşın, Harşit Vadisi'nin oribatid akarları üzerine yapılmış sınırı sayıda çalışma bulunmaktadır (Ağcakaya, 2015; Gökçe, 2015; Ayyıldız et al., 2016; Zoroğlu \& Ayyıldız, 2018). Bunlar arasında Hermanniidae ve Hermanniellidae familyaları hakkında herhangi bir veriye rastlanılmamıştır. Bu çalışmada; Hermannia Nicolet, 1855 ve Hermanniella Berlese, 1908 cinslerine ait akarlar tespit edilerek hem araştırma alanı hem de Türkiye oribatid faunası bilgimize katkı sağlanması amaçlanmıştır. 


\section{Materyal ve Yöntem}

\section{Araştırma alanının tanımı}

Harşit Vadisi; Doğu Karadeniz Bölgesinde yer alan ve Gümüşhane ilinin doğu sınırındaki dağlardan doğup Tirebolu'da Karadeniz'e dökülen Harşit çayının oluşturduğu coğrafi bölgedir (Şekil 1) (Pekin, 2013; Anonim, 2014).

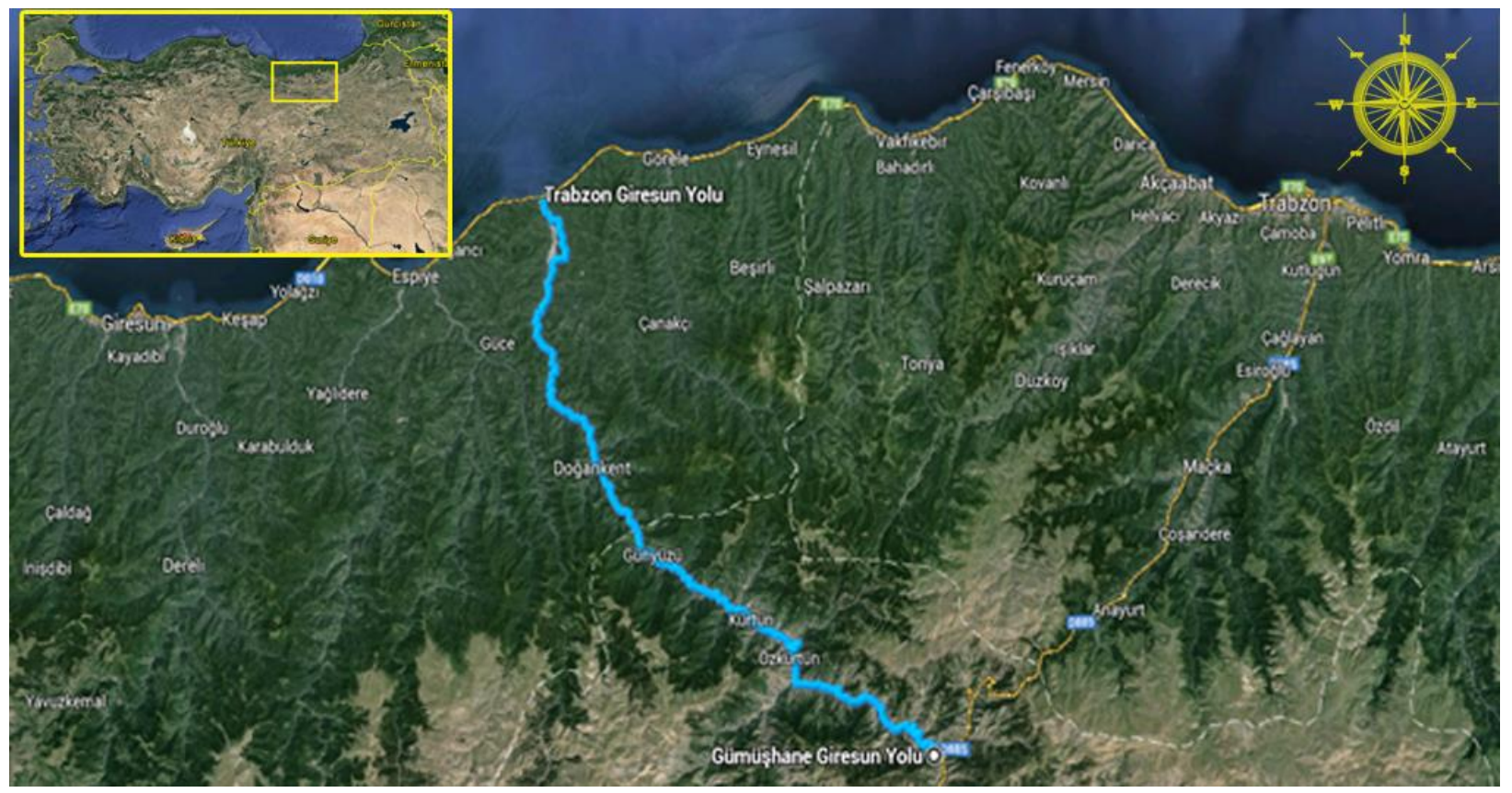

Şekil 1. Araştırma alanı olarak seçilen Harşit Vadisi'nin haritası (Anonim, 2014).

\section{Oribatid akar örneklerinin toplanması, hazırlanması, incelenmesi ve saklanması}

Bu çalışmanın materyalini; Harşit Vadisi'nden 2013 ve 2014 yıllarında toplanan akarlar içerisinden seçilen oribatid akar örnekleri oluşturmaktadır. Burada incelenen akarlar toprak, döküntü, yosun, liken vb. örneklerden Berlese-Tullgren hunilerinden oluşan ayıklama düzeneği kullanılarak özütlenmiş ve içerisinde birkaç damla gliserol ve \%80'lik etil alkol bulunan saklama tüplerine aktarılarak etiketlenip incelenmek üzere muhafaza altına alınmıştır. Mikroskopta incelenecek olan örneklerin temizlenmesi ve ağartılmasında \%80'lik laktik asit kullanılmıştır. Işık mikroskobu incelemeleri çukur lamda laktik asit kullanılarak geçici olarak hazırlanan preparatlar kullanılarak yapılmıştır. İncelenen akarların çeşitli vücut kısımlarına ait ölçüm işlemleri oküler mikrometre kullanılarak gerçekleştirilmiştir. Tarama Elektron Mikroskobu incelemeleri Erciyes Üniversitesi Teknoloji Araştırma ve Uygulama Merkezi (ERÜ-TAUM)'nde yapılmıştır. Tür teşhisinde karşılaştırma materyali ve bu konudaki kaynaklardan yararlanılmıştır (Sitnikova, 1975a, b; Woas, 1978; Balogh \& Mahunka, 1983; Weigmann, 2006; Norton \& Behan-Pelletier, 2009). Teşhis işlemi tamamlanan örnekler etiketlenip, Akaroloji koleksiyonu için muhafaza altına alınmıştır.

\section{Örneklerin toplandığı yerlerin listesi}

Bu çalışmada incelenen Hermannia Nicolet, 1855 ve Hermanniella Berlese, 1908 cinslerine ait akarların bulunduğu örneklemelere ilişkin bilgiler Çizelge 1 'de verilmiştir. 
Çizelge 1. Akar materyalinin toplandığı yerlerin kodu ve bilgileri

\begin{tabular}{|c|c|}
\hline 13 T036 & $\begin{array}{l}\text { ümüşhane-Bayburt il sınırı: Vauk geçidi dere yatağı, } 40^{\circ} 32^{\prime} 44^{\prime \prime K}, 31^{\circ} 28^{\prime} 18 " \mathrm{D}, 1200 \mathrm{~m} \text {, taş üzeri yosun ve liken; } \\
\text { 1.X.2013. }\end{array}$ \\
\hline 3T118 & ümüşhane: Kürtün, Örümcek Ormanları, 40 39' 31"K, 3801' 33"D, 1413 m, dere kenarı taş üzeri yosun; 28.X.2013. \\
\hline $13 T 608$ & $\begin{array}{l}\text { ümüşhane: Şiran, Ara köyü yayla yolu (Torul barajı girişi), } 40^{\circ} 38^{\prime} 41^{\prime \prime K}, 39^{\circ} 08^{\prime} 52 " \mathrm{D}, 714 \mathrm{~m} \text {, kaya altı döküntü; } \\
\text {.X.2014. }\end{array}$ \\
\hline $13 \mathrm{~T} 609$ & 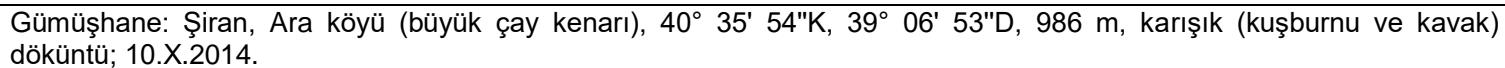 \\
\hline $13 \mathrm{~T} 619$ & $\begin{array}{l}\text { Gümüşhane: Kürtün, Örümcek Ormanları (Şelale civarı), } 40^{\circ} 41^{\prime} 07^{\prime \prime K}, 39^{\circ} 03^{\prime} 05 " \mathrm{D}, 1106 \mathrm{~m} \text {, orman altı karışık döküntü; } \\
\text { 10.X.2014. }\end{array}$ \\
\hline $13 T 620$ & $\begin{array}{l}\text { Gümüşhane: Kürtün, Örümcek Ormanları (Şelale civarı), } 40^{\circ} 41^{\prime} 07^{\prime \prime K}, 39^{\circ} 03^{\prime} 05^{\prime \prime} \mathrm{D}, 1106 \text { m, karışık (söğüt ve kavak) döküntü; } \\
\text { 10.X.2014. }\end{array}$ \\
\hline $13 \mathrm{~T} 621$ & $\begin{array}{l}\text { Gümüşhane: Kürtün, Örümcek Ormanları (Şelale civarı), 40 41' 07"K, 39 03' 05"D, } 1106 \text { m, kaya üzeri döküntü ve toprak; } \\
\text { 10.X.2014. }\end{array}$ \\
\hline $13 \mathrm{~T} 624$ & $\begin{array}{l}\text { Gümüşhane: Kürtün, Örümcek Ormanları (anıt ağacı çevresi), 40 39' 48"K, 390 02' 00"D, } 1289 \text { m, ormangülü altından döküntü; } \\
\text { 10.X.2014. }\end{array}$ \\
\hline $13 T 626$ & $\begin{array}{l}\text { Gümüşhane: Kürtün, Örümcek Ormanları (anıt ağacı çevresi), 40³9' 48"K, 39 02' 00"D, } 1289 \text { m, karışık (meşe ve } \\
\text { ardıç) döküntü; 10.X.2014. }\end{array}$ \\
\hline $13 \mathrm{~T} 650$ & Gümüşhane: Kürtün, Örümcek Ormanları, 40 41' 11"K, 390 02' 47"D, 1046 m, ormangülü altından döküntü; 29.X.2014. \\
\hline $3 T 653$ & Gümüşhane: Kürtün, Örümcek Ormanları, 40 41' 11"K, 39º 02' 47"D, 1046 m, orman altı dök \\
\hline $13 \mathrm{~T} 662$ & iresun: Doğankent, Aydınlar (Güdül), 40 49' 25"K, 38 55' 35"D, 534 m, fındık altından dök \\
\hline $13 T 688$ & $\begin{array}{l}\text { Gümüşhane: Kürtün, Örümcek Ormanları, 40 40' 24"K, 38 59' 53"D, } 1917 \text { m, orman altı yosunlu, çimenli, likenli toprak; } \\
\text { 14.XI.2014. }\end{array}$ \\
\hline $13 T 694$ & $\begin{array}{l}\text { Giresun: Tirebolu, Balçıkbelen Köyü, } 40^{\circ} 58^{\prime} 39^{\prime \prime K}, 38^{\circ} 52^{\prime} 39 " \mathrm{D}, 114 \mathrm{~m} \text {, fındık bahçesinden döküntü ve yosunlu toprak; } \\
\text { 15.XI.2014. }\end{array}$ \\
\hline $13 T 696$ & $" \mathrm{~K}, 38^{\circ} 52^{\prime} 39 " \mathrm{D}, 114 \mathrm{~m}$, ceviz, hurma (Diosp \\
\hline & Giresun: Tirebolu, Balçıkbelen, $40^{\circ} 58^{\prime} 18^{\prime \prime K}, 38^{\circ} 57^{\prime} 39^{\prime \prime D}, 133 \mathrm{~m}$, fındık altından döküntülü tc \\
\hline 702 & Gümüşhane: Kürtün, Kadırga yayla J \\
\hline $13 \mathrm{TT} 704$ & Gümüşhane: Kürtün, Kadırga yayla yolu, $40^{\circ} 4$ \\
\hline $13 T 742$ & köy yakını, 40³8' 28"K, 3907' 36"D, 907 m, \\
\hline $13 T 743$ & olu-Araköy yakını, $40^{\circ} 38^{\prime} 28 " \mathrm{~K}, 39^{\circ} 07^{\prime} 36 " \mathrm{D}, 907 \mathrm{~m}$, \\
\hline $13 T 748$ & $\begin{array}{l}\text { Gümüşhane: Kürtün, Kazıkbeli yayla Yolu-Araköy yakını, } 40^{\circ} 37^{\prime} 58 " \mathrm{~K}, 39^{\circ} 07^{\prime} 03^{\prime \prime D}, 858 \mathrm{~m} \text {, kuşburnu altından döküntü; } \\
09 . \text { IV.2015. }\end{array}$ \\
\hline $3 T 754$ & Gümüşhane: Kürtün, Kazıkbeli yayla Yolu, 39 48' 25"K, 39²2' 49"D, 482 m, fındık altından \\
\hline 758 & Gümüşhane: Kürtün, Kazıkbeli yayla Yolu, 39 48' 25"K, 39²2' 49"D, 482 m, açık alandan çin \\
\hline $13 \mathrm{TT} 60$ & $\begin{array}{l}\text { Gümüşhane: Kürtün, Kazıkbeli yayla Yolu, 40 41' 44"K, 39 10' 43"D, } 1074 \text { m, açık alandan yosunlu } \\
\text { 16.IV.2015. }\end{array}$ \\
\hline 761 & ane: Kürtün, Kazıkbeli yayla Yolu, 40 41' 44"K, 39 10' 43"D, 1074 m, karışık dökün \\
\hline 762 & ne: Kürtün, Kazıkbeli yayla Yolu, $40^{\circ} 41^{\prime} 44^{\prime \prime K}, 39^{\circ} 10^{\prime} 43^{\prime \prime D}, 1074 \mathrm{~m}$, meş \\
\hline $13 T 763$ & Gümüşhane: Kürtün, Kazıkbeli yayla Yolu, 40 41' 44"K, 39 10' 43"D, 1074 m, taş üzeri yosı \\
\hline $13 \mathrm{TT} 66$ & lane: Kürtün, Kazıkbeli yayla Yolu, $40^{\circ} 42^{\prime} 32 " \mathrm{~K}, 39^{\circ} 12^{\prime} 14 " \mathrm{D}, 1241 \mathrm{~m}$, sulu yosun v \\
\hline 767 & olu, $40^{\circ} 42^{\prime} 32^{\prime \prime K}, 39^{\circ} 12^{\prime} 14^{\prime \prime} \mathrm{D}, 1241 \mathrm{~m}$, taş üzeri yos \\
\hline $3 T 770$ & ane: Kürtün, Örümcek Ormanları, 40 41' 06"K, 390 03' 07"D, 729 m, yosunlu ve like \\
\hline $3 T 771$ & ane: Kürtün, Örümcek Ormanları, $40^{\circ} 41^{\prime} 06^{\prime \prime K}, 39^{\circ} 03^{\prime} 07^{\prime \prime D}, 729 \mathrm{~m}$, taş üzeri yosur \\
\hline T772 & Gümüşhane: Kürtün, Örümcek Ormanları, 40 41' 06"K, 390 03' 07"D, 729 m, taş altı döküntü; 16. \\
\hline $13 T 773$ & Gümüşhane: Kürtün, Örümcek Ormanları, 40 41' 06"K, 390 03' 07"D, 729 m, sulu yosun ve çimen; $16 . I V .2015$. \\
\hline $13 \mathrm{~T} 777$ & $\begin{array}{l}\text { lane: Kürtün, Örümcek Ormanları, } 40^{\circ} 41^{\prime} 06 " \mathrm{~K}, 39^{\circ} 03^{\prime} 07 " \mathrm{D}, 729 \mathrm{~m} \text {, likenli, yosunlu ve çimenli toprak; } \\
\text { 15. }\end{array}$ \\
\hline $13 \mathrm{~T} 779$ & $\begin{array}{l}\text { Gümüşhane: Torul, Cehennem Vadisi, Yaylalar kavşağı, } 40^{\circ} 33^{\prime} 13^{\prime \prime K}, 39^{\circ} 28^{\prime} 49^{\prime \prime D}, 1385 \mathrm{~m} \text {, söğüt altından döküntülü } \\
\text { toprak; 14.V.2015. }\end{array}$ \\
\hline 843 & ümüşhane: Kürtün, Örümcek Ormanları, 40 41' 02K, 39 03' 15D, 811 m; karışık yosun, liken ve toprak; 18.VI.2015. \\
\hline $13 \mathrm{~T} 847$ & $\begin{array}{l}\text { üşhane: Kürtün, Örümcek Ormanları, 40 40' 41K, 39 02' 52D, } 1016 \text { m; kayın ve akçaağaç altından döküntü; } \\
\text { I.2015. }\end{array}$ \\
\hline 848 & ne: Kürtün, Örümcek Ormanları, 40 40' 41K, 39² 02' 52D, 1016 m; ormangülü altından dökünti் \\
\hline & ları, 40 41' 07K, 390 03' 28D, $1110 \mathrm{~m}$; meşe altından döküntü; 18.V \\
\hline 850 & ane: Kürtün, Örümcek Ormanları, 40 41' 07K, 390 03' 28D, 1110 m; yosunlu toprak; 18.VI.2015. \\
\hline 851 & üşhane: Kürtün, Örümcek Ormanları, 40 41' 07K, 39 03' 28D, 1110 m; çürümüş kütük; 18.VI.2015. \\
\hline $13 \mathrm{~T} 852$ & $\begin{array}{l}\text { Gümüşhane: Kürtün, Örümcek Ormanları, } 40^{\circ} 41^{\prime} 07 \mathrm{~K}, 39^{\circ} 03^{\prime} 28 \mathrm{D}, 1110 \mathrm{~m} \text {; kayın altından döküntü ve liken; } \\
\text { 18.VI.2015. }\end{array}$ \\
\hline $13 \mathrm{~T} 853$ & $\begin{array}{l}\text { hane: Kürtün, Örümcek Ormanları, 40 41' 07K, 390 03' 28D, } 1110 \text { m; çürümüş meşe kütüğü ve döküntülü toprak; } \\
015 .\end{array}$ \\
\hline & \\
\hline
\end{tabular}




\section{Araştırma Sonuçları ve Tartışma}

Harşit Vadisi'nde 2013 ve 2014 yıllarında yapılan arazi çalışmalarında toplanan materyalden seçilen oribatid akarların incelenmesi sonucu Hermannia (Hermannia) gibba Koch,1839, Hermanniella dolosa Grandjean, 1931 ve Hermanniella picea (Koch, 1839) taksonları belirlenmiştir. Bu taksonlara ait bulgular tarama elektron mikroskobu fotoğrafları ile birlikte aşağıda verilerek tartışılmıştır.

\section{Hermanniidae Sellnick, 1928}

\section{Hermannia Nicolet, 1855}

Tip türü: (Hermannia crassipes Nicolet, 1855) =Nothrus gibbus Koch, 1839

\section{Hermannia (Hermannia) Nicolet, 1855}

\section{Hermannia (Hermannia) gibba Koch, 1839}

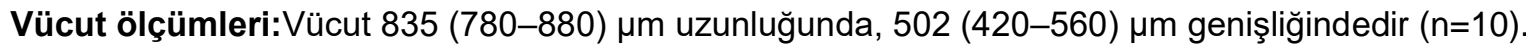

Prodorsum (Şekil 2a, c, d ): Yüzeyi kerotegümentle örtülü olup derisi tanecikli yapıdadır. Rostrum yuvarlak şekildedir. Rostrum kılları ortalama 43 (40-50) $\mu \mathrm{m}$ uzunluğunda, yay şeklinde bükülmüş ve düz yüzeye sahiptir. Lamella kılları ortalama 54 (40-60) $\mu \mathrm{m}$ uzunluğunda ve dar yaprak şeklinde olup rostrum kıllarına olan mesafenin yarısını biraz geçmektedir. İnterlamella kılları prodorsumun en kısa kıllarından olup ortalama 38 (35-40) $\mu \mathrm{m}$ uzunlukta ve geniş yaprak şeklindedir. Sensilluslar ortalama 108 (100-120) $\mu \mathrm{m}$ uzunluğunda, çubuk şeklinde ve yüzeyi düzdür. Botridiyumlar prodorsumun yan kısımlarına yerleşmiş, yuvarlak ve ağızları dışa yöneliktir.

Notogaster (Şekil 2a, c): Görünüşü itibariyle oval şekildedir. Yüzeyi kerotegümentle örtülü olup derisi, çapları 5-7 $\mu \mathrm{m}$ olan yuvarlak ve düzenli taneciklerle donatılmıştır. Tanecikler arasında küçük noktacıklar mevcuttur. Notogasterde çubuksu, biraz yay şeklinde bükülmüş 16 çift kıl mevcut olup ps kılları 40-60 $\mu \mathrm{m}$ diğer kıllar ise 100-130 $\mu \mathrm{m}$ arasında uzunluğa sahiptir.

Gnatozoma (Şekil 2b): Labiogenal eklem tamdır. Subkapitulum dar eklemlidir. Bir çift mentum kılı mevcuttur. Rutellum 3 dişçiklidir.

Karın bölgesi (Şekil 2b, e, f): Apodemata III testere şeklinde dişçikli görünüme sahiptir. Epimer kılları düz ve ince olup dağılımı 3-1-3-4 şeklindedir. Bunlardan 3b, 3c, 4c ve 4d kılları diğerlerinin yaklaşık

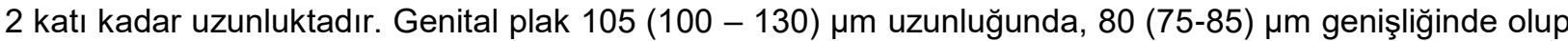
hemen hemen geniş̧̧e kama şeklinde görünüme sahiptir. Genital plakta 6-20 um uzunluğunda 9 çift kıl mevcuttur. Aggenital bölgede 2 çift kıl vardır. Anal plak ortalama 197 (180-230) $\mu \mathrm{m}$ uzunluğunda ve 68 (60-70) $\mu \mathrm{m}$ genişliğinde olup, 2 çift anal kıl taşımaktadır. Adanal kıllar, 20-25 $\mu \mathrm{m}$ uzunlukta, kaidede geniş uca doğru daralan tipte olup 3 çifttir.

Bacaklar: Bütün bacaklar bir tırnaklıdır. Tırnaklar 50-60 $\mu \mathrm{m}$ uzunluğundadır. I. bacakta solenidiyumlar dâhil kıl dağılımı (trokanter - tarsus) : 6-5-6-26-1, IV. Bacakta ise 1-3-4-5-16 şeklindedir.

Incelenen materyal: 13T118: 13 ergin, 13T688: 30 ergin, 13T702: 36 ergin, 13T704: 15 ergin.

Hermannia (Hermannia) gibba Koch,1839: Holarktik ve Seyşel Adaları'nda yayılış gösterir (Sitnikova, 1975a; Woas, 1978; Balogh \& Mahunka, 1983; Subias, 2004, updated 2018; Weigmann, 2006). Bu tür ülkemizde daha önce Erzurum ili Uzunoluk ormanında yaşayan bazı oribatid akarlar ve bunlardan izole edilen funguslar üzerine yapılan bir çalışmada tespit edilmiştir (Yalçın et al., 2013). Adı geçen çalışmada, Yalçın et al. (2013) SEM görüntüleri ile birlikte kısa bir tanım vermişlerdir: "Vücut 770 $\mu \mathrm{m}$ uzunluğunda $570 \mu \mathrm{m}$ genişliğindedir. Sensillus çomak şeklinde ve düz yapılıdır. İki çift aggenital, dokuz çift genital kıl vardır. Epimeral kıl formülü 3-1-3-4 şeklindedir. Keliser parmağı dört dişçikli, rutellum üç loblu, mentum kıılları düz yapılı olup I. epimeral bölgeye kadar uzanmıştır. I. ve II. femurlar genişlemiş lamel şeklindedir. Notogasterin yüzeyi yuvarlak şekilde granüllü desene sahiptir, kılları uzun, yay şeklinde bükülmüş olup kılıca benzemektedir." Araştırıcılar inceledikleri örneği 2120 m yükseklikte taş üzeri liken ve yosundan toplamışlardır. 

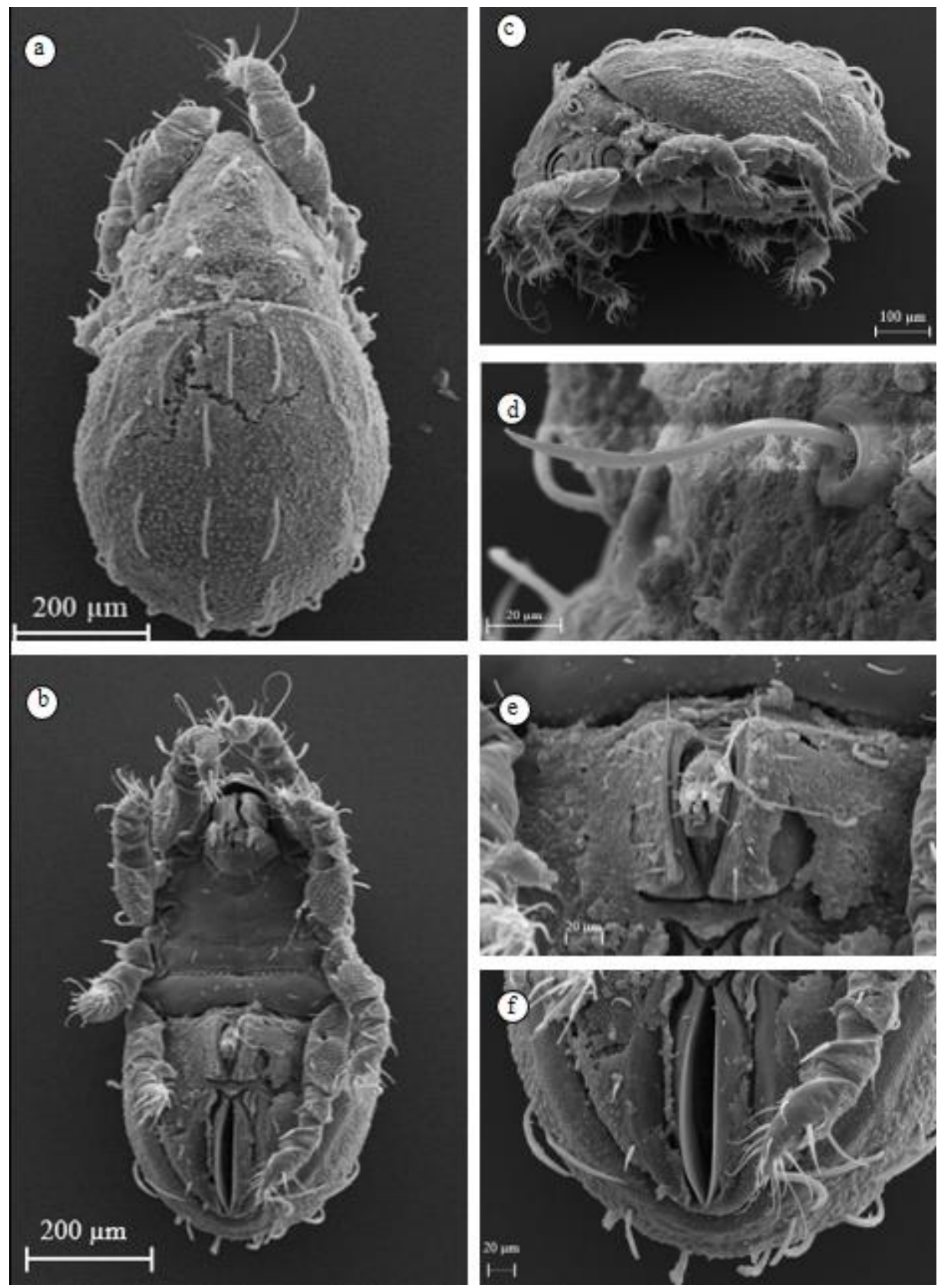

Şekil 2. Hermannia (Hermannia) gibba Koch,1839 a) Sırttan görünüşü; b) Karından görünüşü; c) Yandan görünüşü; d) Sensillus; e) Genital plak; f) Anal plak.

Bu tür için vücut uzunluğu 770-940 $\mu \mathrm{m}$, genişliği ise 420-550 $\mu \mathrm{m}$ olarak verilmiştir (Sitnikova, 1975a; Woas, 1978; Balogh \& Mahunka, 1983; Weigmann, 2006). Örneklerimizde uzunluk ve genişlik değerleri sırasıyla 835 (780-880) ve 502 (420-560) $\mu \mathrm{m}$ olarak tespit edilmiştir. Bu verilerden yola çıkarak örneklerimizin vücut büyüklüğünün tür için daha önce verilen vücut büyüklüğü ölçüm verileri ile uyum içerisinde olduğu anlaşılmaktadır.

Örneklerimizde lamella kılları Balogh \& Mahunka (1983) tarafından verilen şekilde olduğu gibi rostrumun ucuna kadar uzanmamaktadır. Oysa Weigmann (2006) ve Woas (1978) tarafından verilen 
şekillerde ise rostrumun ucuna kadar ulaşmaktadır. Bu farklılığın hayvanın bombeli yapısı nedeniyle preparasyondan kaynaklanabileceği kanısındayız. Woas (1978) karın bölgesine ilişkin hem şekil hem tanımlama yapmış iken diğer araştırıcılar (Sitnikova, 1975a; Balogh \& Mahunka, 1983; Yalçın et al., 2013) karın bölgesine ilişkin ayrıntılı bilgi ve şekil vermemişlerdir. Bu bakımdan incelediğimiz örneklerin Woas (1978) tarafından verilen karın bölgesi özellikleri ile de uyum içerisinde olduğu anlaşılmaktadır. Weigmann et al. (2015) bu türü arborikol, toprak kolonizeri, epilitik ve epifitik olarak tanımlamıştır. Örneklerimizi topladığımız habitatlar incelendiğinde çoğunlukla yosunda bulunduğu aynı şekilde Yalçın et al. (2013)'nin de taş üzeri liken ve yosundan toplamış olmaları bu türün Weigmann et al. (2015) tarafından verilen yaşam biçimi şekilleri ile uyum içerisinde olduğu anlaşılmaktadır.

\section{Hermanniellidae Grandjean, 1934}

\section{Hermanniella Berlese, 1908}

Tip türü: Hermannia granulata Nicolet, 1855

\section{Türkiye'den Bilinen Hermanniella Cinsine Ait Türler İçin Teşhis Anahtarı}

1. Notogaster tritonimf derisi altında adacıklarla (areolae) örtülü ............................. 2

- Notogaster tritonimf derisi altında adacık taşımaz; yarık şeklinde, çoğunlukla tek, bazen 2-3 yarığın birleştiği gözenekler taşır; $f_{1}$ kılları yassılaşmış ve uca doğru genişlemiş, tüylü; $h_{3}$ kılları çok küçük Hermanniella multipora Sitnikova, 1974

2. Adacıklar uzunluğuna sıralar halinde gruplanmış, $h_{3}$ kılları notogasterin diğer kıllarından daha küçük Hermanniella picea (C. L. Koch, 1839)

- Gözenekler iplik şeklinde zincirlerle bağlantılı, belirgin olarak altıgen şeklinde yapı oluşturur; $f_{1}$ kılları geniş, kalınlaşmış ve yaprak şeklinde Hermanniella dolosa Grandjean, 1931

\section{Hermanniella dolosa Grandjean, 1931}

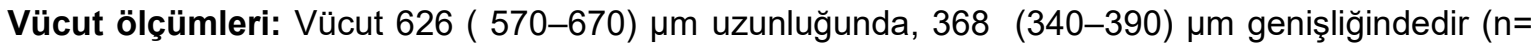
6). Prodorsum (Şekil 3a, d, g): Uzunluğu, yandan görünüşte notogaster uzunluğunun yarısından daha kısadır. Yüzeyi kerotegümentle örtülüdür. Kerotegüment beşgen veya altıgen şeklinde ağsı bir görünüme sahip olup çok küçük taneciklerden oluşan küre benzeri tümsecikli yapılardan ibarettir. Rostrum yuvarlaklaşmıştır. Rostrum kılları 30 (25-35) $\mu \mathrm{m}$ uzunlukta ve düz olup uca doğru incelmektedir. Rostrum kılları arasındaki mesafe 40 (38-42) $\mu \mathrm{m}$ kadardır. Lamella kılları rostrum kılları gibi benzer uzunlukta olup üzeri yoğun olarak dikenli, kalın ve orak çeklinde bir görünüme sahiptir. Lamella kılları arasındaki mesafe

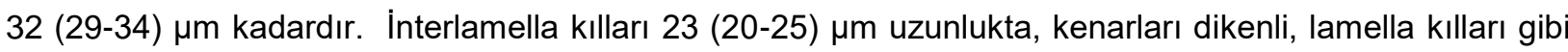
kalın ve uca doğru incelmektedir. İnterlamella kılları arasındaki mesafe 32 (29-34) $\mu \mathrm{m}$ kadardır. Botridiyumlar prodorsumun kenarlarına yerleşmiş olup ağız kısımları dışa yöneliktir. Sensilluslar ortalama 75 (73-78) um uzunluğunda, kaideye yakın kısımda dirsek oluşturarak uç kısımda dar iğimsi ve dikenli bir baş kısmına sahiptir.

Notogaster (Şekil 3a, c-f): Notogaster oval, uzunluğunun genişliğine oranı yaklaşık 1,6 kadardır. Kerotegüment, koni şeklinde (küçük büyültmelerde diken şeklinde) tepede yuvarlaklaşmış yapılara sahip olup aralarında küre şeklinde tanecikler barındııı. Kerotegümentin altında deri, çokgen şeklinde ve köşelerinde yuvarlak taneciklerin olduğu ağsı desene sahiptir. Notogasterde 15 çift kıl vardır. Notogaster 
kılları düz ve kerotegümentsiz yapıdadır. $f_{1}$ kılları diğer notogaster kıllarından farklı olarak genişlemiş yaprak şeklinde bir görünüme sahiptir. $h$ ve $p s$ dizilerindeki kıllar diğer notogaster kıllarına nispetle kısa ve biraz genişlemiştir. Kıllar uzunlukları itibariyle müteakip kılların çıkış yerlerine kadar ulaşmamaktadır. Opistonotal bezler kerotegüment ile örtülü olup notogasterin her iki yanından yaklaşık $32 \mu \mathrm{m}$ kadar çıkıntı oluşturmaktadır.

Gnatozoma (Şekil 3i): Subkapitulum iki eklemlidir. Mentum kerotegümentle örtülüdür, uzunluğunun yaklaşık 1,5 katı kadar genişliktedir. Subkapitulum kıllarından a kılı diğer subkapitulum kıllarından ( $h$ ve $m$ ) daha uzundur.

Karın bölgesi (Şekil 3h-k): Ağsı yapıda kerotegümentle örtülüdür. Epimer bölgesinde kılların dağılımı 3-1-3-3 şeklinde olup kısa ve düzdür. Ancak $1 b, 3 c$ ve $4 c$ kılları diğer epimer kıllarından daha uzundur. Genital plak ile anal plak arası mesafe ortalama 30 (28-31) $\mu$ m'dir. Genital plak ortalama 115 (110-120) $\mu \mathrm{m}$ uzunluğunda ve ortalama 100 (90-110) $\mu \mathrm{m}$ genişliğinde olup 6 çift kıl taşımaktadır. Bunlardan $g_{5}$ kılı diğer genital kıllardan daha uzun ve kalın yapıdadır. Bir çift aggenital kıl mevcuttur. Anal plak ortalama $158(150-160) \mu \mathrm{m}$ uzunluğunda ve 130 (120-150) $\mu \mathrm{m}$ genişliğinde olup 2 çift kıl taşımaktadır. Bunlardan $a n_{1}$ kılı $a n_{2}$ kılından daha uzundur. Adanal plakta 3 çift adanal kıl mevcut olup bunlardan $\mathrm{ad}_{1}$ kılı diğer adanal kılların uzunluğunun yaklaşık 2,5-3 katı kadar uzunluktadır.

Bacaklar: Bacak yüzeyleri kerotegüment ile örtülüdür. Bütün bacaklar bir tırnaklı olup tırnak uzunluğu ortalama 45 (40-50) $\mu$ m'dir.

İncelenen materyal: 13T036: 2 ergin, 13T608: 4 ergin, 13T609: 26 ergin, 13T619: 1 ergin, 13T621: 8 ergin, 13T624: 11 ergin, 13T626: 7 ergin, 13T650: 15 ergin, 13T653: 1 ergin, 13T662: 6 ergin, 13T688: 1 ergin, 13T694: 6 ergin, 13T696: 5 ergin, 13T698: 3 ergin, 13T702: 7 ergin, 13T704: 11 ergin, 13T742: 4 ergin, 13T748: 9 ergin, 13T754: 1 ergin, 13T758: 3 ergin, 13T760: 10 ergin, 13T761: 31 ergin, 13T762: 8 ergin, 13T763: 1 ergin, 13T770: 8 ergin, 13T771: 3 ergin, 13T772: 9 ergin, 13T773: 3 ergin, 13T777: 23 ergin, 13T779: 11 ergin, 13T843: 9 ergin, 13T847: 2 ergin, 13T848: 9 ergin, 13T849: 8 ergin, 13T850: 7 ergin, 13T851: 7 ergin, 13T852: 10 ergin, 13T853: 1 ergin, 13T854: 1 ergin.

Hermanniella dolosa Grandjean, 1931: Palearktik bölgede yayılış gösterir (Grandjean, 1931; Sitnikova, 1975a; Subias, 2004, updated 2018; Weigmann, 2006). Toluk et al.(2006) tarafından daha önce Yozgat Çamlığı Milli Parkı'ndan verilen H. punctulata'ya ait örneklerin H. dolosa Grandjean, 1931'e ait olduğu kanısındayız. Bu tür için vücut uzunluğu 545-670 $\mu \mathrm{m}$ aralığında verilmiştir (Grandjean, 1931; Sitnikova, 1975a; Weigmann, 2006). Toluk et al. (2006) vücut uzunluğunu 629 (540-690) $\mu \mathrm{m}$, genişliğini ise 362 (320-400) $\mu \mathrm{m}$ olarak vermişlerdir. Örneklerimizde vücut uzunluğu 626 ( 570-670) $\mu \mathrm{m}$, genişliği ise 368 (340-390) $\mu \mathrm{m}$ olarak tespit edilmiştir. Bu verilerden örneklerimizin vücut büyüklüğünün tür için daha önce verilen vücut büyüklüğü ölçüm verileri ile uyum içerisinde olduğu anlaşılmaktadır. Bu türün en önemli özelliği notogaster bölgesindeki desenin poligonal ağsı yapıda olması ve $f_{1}$ kıllarının geniş ve kalınlaşmış yaprak şeklinde bir görünüme sahip olmasıdır. Örneklerimiz tüm bu özellikleri bakımından diğer araştırıcılar tarafından bu türe ilişkin verilen tanıtıcı özellikler ile tam bir uyum içerisindedir (Grandjean, 1931; Sitnikova, 1975a; Weigmann, 2006). 

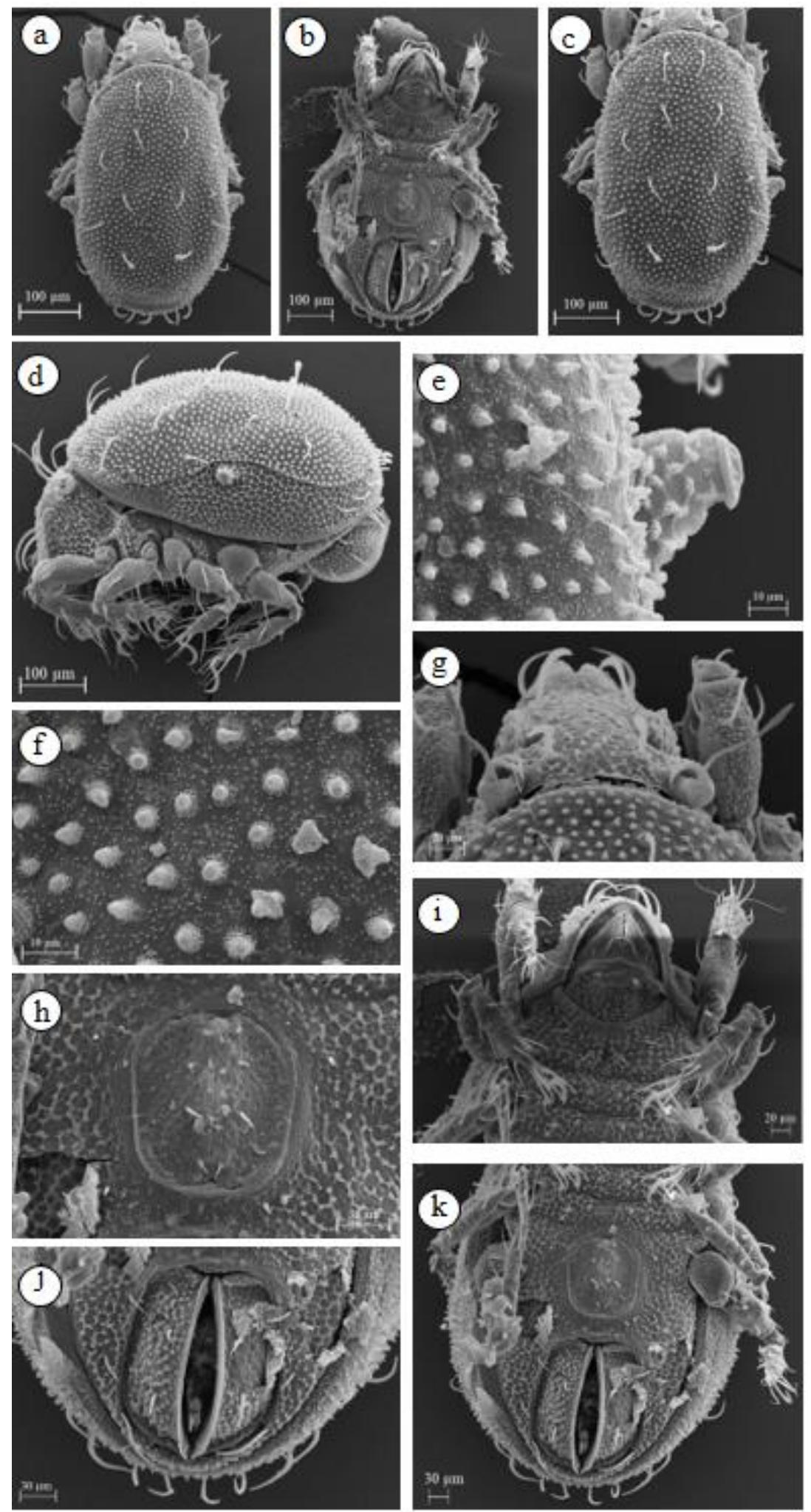

Şekil 3. Hermanniella dolosa Grandjean, 1931 a) Sırttan görünüşü; b) Karından görünüşü; c) Notogaster; d) Yandan görünüşü; e) Opistonotal bez; f) Notogaster deseni; g) Prodorsum; h) Genital plak; i) Gnatozoma ve epimeral bölge; j) Anal plak; k) Genito-anal bölge. 


\section{Hermanniella picea (Koch, 1839)}

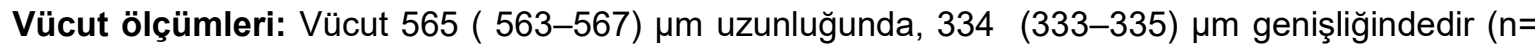
2). Prodorsum (Şekil 4a, c, d): Yüzeyi kaba yapıda kerotegümentle örtülüdür. Rostrum yuvarlaklaşmıştır. Rostrum kılları $33 \mu \mathrm{m}$ uzunlukta ve düz olup uca doğru incelmektedir. Rostrum kılları arasındaki mesafe $72 \mu \mathrm{m}$ kadardır. Lamella kılları yay şeklinde uçta içeri doğru bükülmüş, yaklaşık $72 \mu \mathrm{m}$ uzunluğunda ve yüzeyi dikenlerle örtülüdür. Lamella kılları arasındaki mesafe $72 \mu \mathrm{m}$ kadardır. İnterlamella kılları $50 \mu \mathrm{m}$ uzunlukta, kenarları dikenli, lamella kılları gibi kalın ve uca doğru incelmektedir. İnterlamella kılları arasındaki mesafe $79 \mu \mathrm{m}$ kadardır. Botridiyumlar prodorsumun kenarlarına yerleşmiş olup ağız kısımları dışa yöneliktir. Sensilluslar ortalama $62 \mu \mathrm{m}$ uzunluğunda (sap kısmı $19 \mu \mathrm{m}$, iğimsi şekildeki baş kısmı ise $43 \mu \mathrm{m}$ ) kaideye yakın kısımda dirsek oluşturarak uç kısımda iğimsi ve dikenli bir baş kısmına sahiptir.

Notogaster (Şekil 4a, b, e): Notogaster oval, uzunluğunun genişliğine oranı yaklaşık 1,45 kadardır. Kerotegüment, koni şeklinde (küçük büyültmelerde diken şeklinde) yapılara sahiptir. Kerotegümentin altında deri, uzunluğuna sırada küçük nokta çukurluklu 1 veya 2'li gruplar halinde dizilmiş desene sahiptir. Notogasterde 15 çift kıl mevcut olup uzunlukları 28 - $35 \mu \mathrm{m}$ arasında değişmektedir. Notogasterin arka kenarındaki kıllar uzun ve çubuk şeklinde iken $h_{3}$ kılı daha kısadır. Kıllar uzunlukları itibariyle müteakip kılların çıkış yerlerine kadar ulaşmamaktadır. Opistonotal bezler kerotegüment ile örtülü olup notogasterin her iki yanından yaklaşık $26 \mu \mathrm{m}$ kadar çıkıntı oluşturmaktadır.

Gnatozoma: Subkapitulum iki eklemlidir. Mentum kerotegümentle örtülüdür.

Karın bölgesi: Kerotegümentle örtülüdür. Epimer bölgesinde kılların dağılımı 3-1-3-3 şeklindedir. Genital plak 6 çift, anal plak 2 çift ve adanal plak ise 3 çift kıl taşır.

Bacaklar: Bacak yüzeyleri kerotegüment ile örtülüdür. Bütün bacaklar bir tırnaklıdır.

İncelenen materyal: 13T620: 2 ergin (1 tanesi SEM incelemesi için kullanıldı.).

Hermanniella picea (Koch, 1839): Holarktik ve Oriental bölgede yayılış göstermektedir (Van der Hammen, 1952; Sitnikova, 1975a; Marshall et al., 1987; Subias, 2004, updated 2018; Weigmann, 2006). Bu tür Türkiye faunası için yeni kayıttır. Toluk et al. (2006) tarafından daha önce Yozgat Çamlığı Milli Parkı'ndan verilen $H$. punctulata'ya ait örneklerin $H$. dolosa Grandjean, 1931'e ait olduğu kanısındayız. Zira bu tür, belirgin altıgen şeklindeki notogaster deseni ile $H$. picea'dan ayrılmaktadır. Bu tür; çeşitli araştırıcılar tarafından H. punctulata Berlese, 1908'in sinonimi olarak düşünülmüştür (Marshall et al., 1987; Mahunka ve Mahunka-Papp, 1995; Subias, 2004). Biz de tanım ve şekillerin incelenmesi sonucu; bu çalışmada, önerilen sinonimliğin uygun olduğu kanısındayız.

Bu tür için vücut uzunluğu 516 - $700 \mu \mathrm{m}$, genişliği ise 299-380 $\mu \mathrm{m}$ aralığında verilmiştir (Berlese, 1908; Sitnikova, 1975a; Weigmann, 2006). Örneklerimizde ise vücudun 565 ( 563-567) um uzunluğunda ve 334 (333-335) $\mu \mathrm{m}$ genişliğinde olduğu tespit edilmiştir. Bu verilerden hareketle örneklerimizin vücut büyüklüğünün tür için daha önce verilen vücut büyüklüğü ölçüm verileri ile uyum içerisinde olduğu anlaşılmaktadır. Bu türe ilişkin sadece notogasterdeki desene yönelik şekiller verildiğinden ayrıntılı bir karşılaştırma yapma imkânı bulunmamaktadır ancak anahtarlarda verilen özellikler dikkate alındığında örneklerimizin bilinenlerle benzer yapıda olduğu kanısına varılmıştır (Berlese, 1908; Van der Hammen, 1952; Sitnikova, 1975a; Weigmann, 2006). 

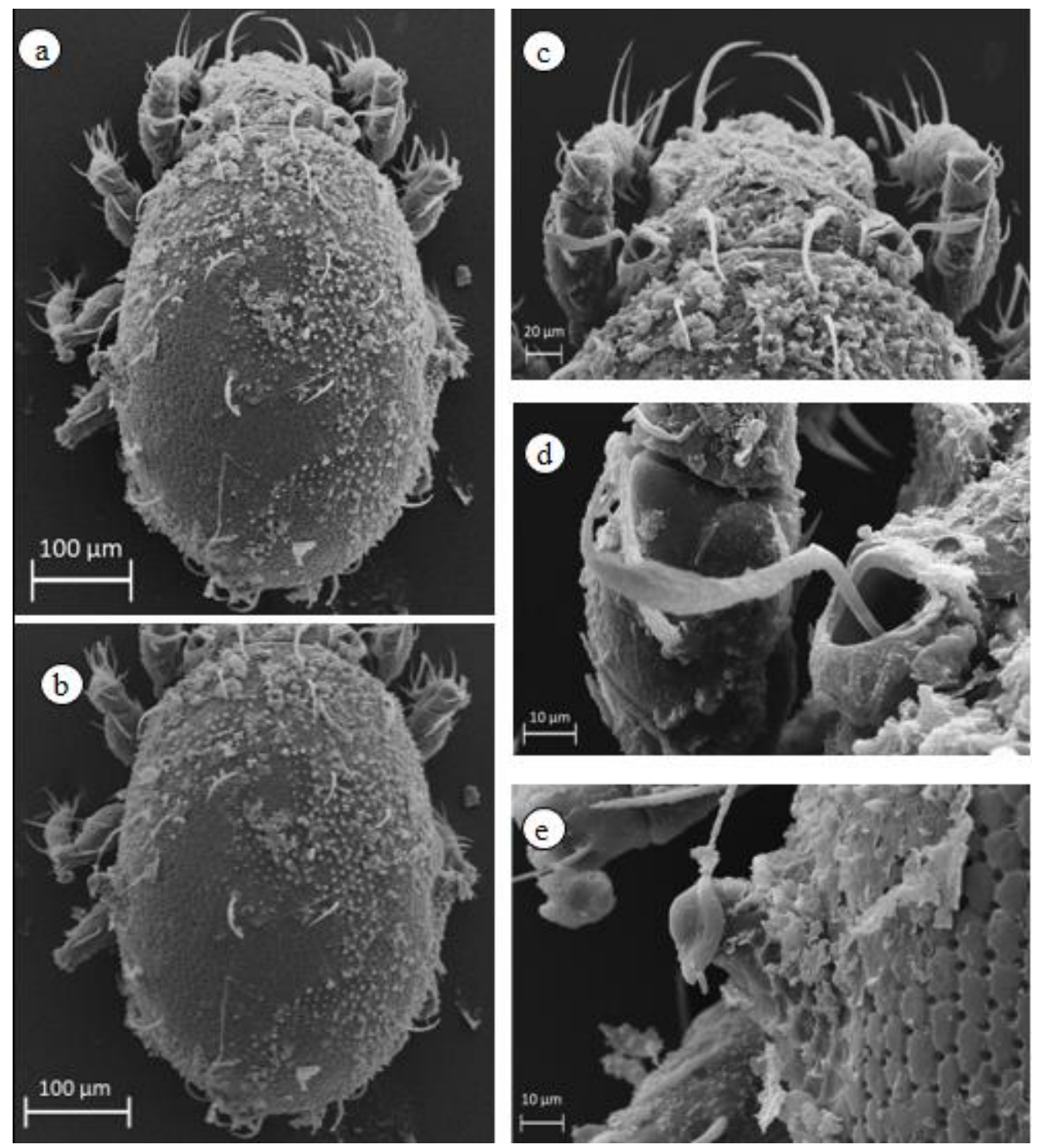

Şekil 4. Hermanniella picea (Koch, 1839) a) Sırttan görünüşü; b) Notogaster; c) Prodorsum; d) Sensillus; e) Notogaster kerotegümenti ve opistonotal bez.

\section{Sonuç}

Araştırma alanından Hermannia (Hermannia) gibba Koch,1839, Hermanniella dolosa Grandjean, 1931 ve Hermanniella picea (Koch, 1839) taksonları tespit edilmiştir. Bunlardan Hermanniella picea (Koch, 1839) ülkemiz faunası için yeni kayıttır. Ülkemizin bulunduğu Palearktik bölgede Hermannia'dan 28 ve Hermanniella'dan 23 taksonun bilindiği göz önüne alındığında daha fazla çalışmanın yapılması gerektiği açıktır. Bu nedenle ülkemizin değişik yerlerinden ve çeşitli yaşam alanlarından örneklemeler yapılarak oribatid akar faunası bilgimize katkı yapılması gerektiği düşüncesindeyiz. 


\section{Teşekkür}

Bu çalışma; Erciyes Üniversitesi Fen Bilimleri Enstitüsü tarafından 13.08.2018 tarihinde kabul edilen ilk yazarın Yüksek Lisans Tezinden üretilmiştir. Çalışma materyalini sağlayan Erzincan Binali Yıldırım Üniversitesi öğretim üyesi Sayın Prof. Dr. Salih DOĞAN ve arkadaşlarına, laboratuvar çalışmaları esnasındaki yardımları için Sayın Dr. Abdulkadir TAŞDEMiR ile tarama elektron mikroskobu incelemelerinde yardımlarını esirgemeyen Erciyes Üniversitesi Teknoloji Araştırma ve Uygulama Merkezi personelleri Sayın Öğr. Gör. Altınay BOYRAZ ve Sayın Öğr. Gör. İhsan AKŞiT’e teşekkür ederiz.

\section{Yararlanılan Kaynaklar}

Ağcakaya, P., 2015. Harşit Vadisi'nin Liacarid Akarları (Acari, Oribatida, Liacaridae) Üzerine Taksonomik Araştırmalar. Erciyes Üniversitesi, (Basılmamış) Yüksek Lisans Tezi, Kayseri, 59 s.

Anonim, 2014. Harşit Çayı, Gümüşhane-Giresun, Google Earth, V 7.1.2.2041. (Web sayfası: http://www.earth. google.com), (Erişim tarihi: Aralık 2017).

Ayyıldız, N. \& A. Toluk, 2016. Contributions to the Turkish oribatid mite fauna (Acari: Oribatida). Türkiye Entomoloji Dergisi, 40(1): 73-85.

Ayyıldız, N., A. Toluk, A. Taşdemir, M. Taşkıran \& B. Arık, 2016. Some oribatid mites (Acari) from the Harşit Valley (Turkey). Symposium on EuroAsian Biodiversity (SEAB-2016), 23-27 May 2016, Antalya, Turkey, p. 497.

Balogh, J. \& S. Mahunka, 1983. The Soil Mites of the World. Volume I. Primitive Oribatids of the Palaearctic Region. Elsevier, Amsterdam, Netherlands, $372 \mathrm{pp}$.

Berlese, A., 1908. Elenco di generi e specie nuove di Acari. Redia, 5: 1-15.

Dhooria, M. S., 2016. Fundamentals of Applied Acarology. Springer Science and Business Media, Singapore, $470 \mathrm{pp}$.

Evans, G. O., 1992. Principles of Acarology. Cambridge University Press, Wallingford, 563 pp.

Gökçe, S., 2015. Harşit Vadisi'nin Phenopelopid Akarları (Acari, Oribatida, Phenopelopidae) Üzerine Taksonomik Araştırmalar. Erciyes Üniversitesi, (Basılmamış) Yüksek Lisans Tezi, Kayseri, $69 \mathrm{s.}$

Grandjean, F., 1931. Observations sur les Oribates (2e série). Bulletin du Muséum National d'Histoire Naturelle, (2), 3: 651-665.

Hammen, L., van der, 1952. The Oribatei (Acari) of the Netherlands. Zoologische Verhandelingen, Leiden, 17: 1-139.

Mahunka, S. \& L. Mahunka-Papp, 1995. The Oribatid Species Described by Berlese (Acari). Hungarian Natural History Museum, Budapest, $325 \mathrm{pp}$.

Marshall, V. G., R. M. Reeves \& R. A. Norton, 1987. Catalogue of the Oribatida (Acari) of Continental United States and Canada. Memoirs of the Entomological Society of Canada, 119 (139): 1-418.

Masuko, K., 1994. Specialized predation on oribatid mites by two species of the ant genus Myrmecina (Hymenoptera: Formicidae). Psyche, 101: 159-173.

Norton, R. A., 1990. “Acarina: Oribatida, pp. 779-803". In: Soil Biology Guide (Ed: Dindal, D.L.). John Wiley and Sons, USA, $1349 \mathrm{pp}$.

Norton, R. A. \& V. M. Behan-Pelletier, 2009. "Suborder Oribatida, pp. 430-564". In: A Manual of Acarology, 3rd ed. (Eds: Krantz, G.W. \& D.E. Walter). Texas Tech University Press, USA, 807 pp.

Pekin, S., 2013. Harşit Havzasının Tarihi Coğrafyası. (Web sayfası: http://www.suleymanpekin. com/98_icerik-harsithavzasinin-tarihi-cografyasi.aspxm), (Erişim tarihi: Aralık 2017).

Sitnikova, L. G., 1975a. "Superfamily Hermannoidea Balogh, 1972, 101-104". In: Sarcoptiformes. Oprodelitel' obitajuschtschich w potschwe kleschtschej (Eds: Ghilarov, M.S. \& D.A. Krivoluckij). Ist. Nauka, Moskau, 491 pp. 
Sitnikova, L. G., 1975b. "Superfamily Hermannielloidea Dubinin, 1954, 105-111". In: Sarcoptiformes. Oprodelitel' obitajuschtschich w potschwe kleschtschej (Eds: Ghilarov, M.S. \& D.A. Krivoluckij). Ist. Nauka, Moskau, 491 pp.

Subías, L. S., 2004. Listado sistemático, sinonímico y biogeográfico de los ácaros oribátidos (Acariformes: Oribatida) del mundo (excepto fósiles). Graellsia, 60 (número extraordinario) 3-305. (Web page: http://www.ucm.es/info/ zoo/Artropodos/Catalogo.pdf), (Access date: March 2019).

Toluk, A., E. Koçoğlu, A. Taşdemir, S. Per \& N. Ayyıldız, 2006. Yozgat Çamlığı Milli Parkı'ndan Türkiye faunası için yeni bir oribatid akar (Acari, Oribatida) türü: Hermanniella punctulata Berlese, 1908. Türkiye Entomoloji Dergisi, 30: 275-283.

Weigmann, G., 2006. Hornmilben (Oribatida). Die Tierwelt Deutschlands, Begründet 1925 von Friedrich Dahl, 76. Teil. Goecke \& Evers, Keltern, 520 pp.

Weigmann, G., F. Horak, K. Franke \& A. Christian, 2015. Verbreitung und Ökologie der Hornmilben (Oribatida) in Deustschland. Peckiana, 10: 1-171.

Wissuwa, J., J-A. Salamon \& T. Frank, 2013. Oribatida (Acari) in grassy arable fallows are more affected by soil properties than habitat age and plant species. European Journal of Soil Biology, 59: 8-14.

Woas, S., 1978. Die arten der gattung Hermannia Nicolet, 1855 (Acari, Oribatei) 1. Beiträge zur naturkundlichen Forschung in Südwestdeutschland, 37: 113-141.

Yalçın, S., S. Doğan \& N. Ayyıldız, 2013. Uzunoluk Ormanı'nda (Erzurum) yaşayan bazı oribatid akarlar (Acari: Oribatida) ve onlardan izole edilen mikrofunguslar. Türkiye Entomoloji Dergisi, 37(1): 117-131.

Zoroğlu, R. \& N. Ayyıldız, 2018. Harşit Vadisi'nin achipteriid akarları (Acari, Oribatida, Achipteriidae). Bitki Koruma Bülteni, 58(2): 63-69. 